\title{
RESIDUES OF ANTIBIOTICS IN RAW HONEYS FROM DIFFERENT APIARIES OF NORTHERN INDIA AND EVALUATION OF HUMAN HEALTH RISKS
}

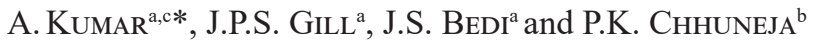

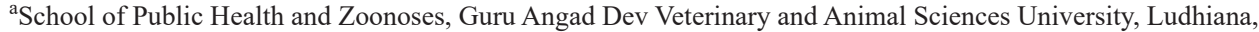 \\ 141004. India \\ ${ }^{b}$ Department of Entomology, Punjab Agricultural University, Ludhiana, 141004. India \\ ${ }^{\mathrm{c}} \mathrm{CSK}$ HP Agricultural University, Palampur, 176062. India
}

(Received: 19 February 2020; accepted: 22 April 2020)

\begin{abstract}
Indiscriminate use of antibiotics in apicultural practices may lead to contamination of otherwise healthy and naturally produced honey. Contamination not only affects honey quality but also pose significant health risks to consumers. In this context, one hundred raw honey samples from India were analysed for presence of antibiotic residues. For determination of oxytetracycline and erythromycin, high performance liquid chromatography and for chloramphenicol, enzyme immunoassay based validated procedures were used. Oxytetracycline and erythromycin with concentrations above maximum tolerance limits were detected in $24 \%$ and $2 \%$ samples, respectively. None of the samples contained chloramphenicol residues. Although, total dietary intake of detected antibiotics through honey was found to be $<1 \%$ of their acceptable daily intake values, the presence of antibiotics in honey is an alarming health concern for people following customary honey feeding. The outcomes underline the need of inter-sectoral approaches to create awareness among beekeepers regarding health risks associated with residues of antibiotics in honey and merits of approved apicultural practices. Therefore, to meet global food safety requirements, continual residue monitoring schemes along with enlightenment of beekeepers on scientific beehive management and risks associated with incautious apicultural practices are of vital importance.
\end{abstract}

Keywords: health risks, antibiotics, raw honey, HPLC, ELISA, India

Honey is produced by honey bees that collect nectar from various floral sources. India is one of the leading producers and exporters of honey in the world. Owing to their diverse botanical sources, Northern Indian states such as Himachal Pradesh, Punjab, Haryana, Rajasthan, Uttarakhand, and Uttar Pradesh are front runners in honey production (KUMAR et al., 2018). Global honey market is also anticipated to register about 2.4 million tons of honey production by 2022, and a good deal of this growth can be attributed to common image of honey as a simple and natural product devoid of contaminants. Although, beehive products are considered healthy and energetic, due to unapproved beekeeping practices and rising environmental pollution, they are now being found to be contaminated with various xenobiotics such as antibiotics, pesticides, and acaricides. The non-judicious use of antibiotics against bacterial foulbrood diseases of honey bees often lead to contamination of honey. The contaminated honey may cause harmful human health effects, such as yellowing of teeth, gastrointestinal disturbances, aplastic anaemia, allergic reactions, and may contribute towards emergence of antibiotic resistant bacteria (VENABLE et al., 2014).

\footnotetext{
* To whom correspondence should be addressed.

Phone: +91 9418002944; fax: +911894 230327; e-mail: dratu19@gmail.com
} 
Animal origin foods (milk, meat, eggs, and fish) have drawn attention, but safety and quality issues pertaining to honey have been largely neglected by veterinary scientists. As per OIE, bee colony is regarded as animal and apiary as single epidemiological unit. Therefore, research by animal scientists for quality control of honey is vital for welfare of bee farmers as well as for food safety and quality assurance. There are international reports of antibiotics detected in honey, but such reports from India, especially in raw honey, is meagre (SoLOMON et al., 2006; MAHMOUDI et al., 2014). Hence, present study was envisaged with the objective to determine residues of most commonly used antibiotics in raw honeys and assessment of human health risks.

\section{Materials and methods}

\subsection{Chemicals and reagents}

All chemicals (HPLC or analytical grade) were procured from Merck Life Sciences, India (EMPARTA®). Deionised water was purified by Milli-Q system of Millipore, Merck KGaA, Germany. Oxytetracycline and erythromycin standards were procured from Sigma Aldrich (Fluka Analytical), Germany. Solid phase extraction cartridges were purchased from Waters Ltd., USA. Standard stock solutions of antibiotics were prepared by diluting appropriate amount of reference standard in organic solvents (methanol for oxytetracycline and acetonitrile for erythromycin) to achieve a final concentration of $1 \mathrm{mg} \mathrm{ml}^{-1}$. Stock solutions were stored at $4{ }^{\circ} \mathrm{C}$ for about 4 weeks. Working standards solutions of oxytetracycline (2.5$\left.100 \mathrm{ng} \mathrm{g}^{-1}\right)$ and erythromycin $\left(25-1000 \mathrm{ng} \mathrm{g}^{-1}\right.$ ) were prepared fresh by appropriate dilution of standard stock solutions with their respective mobile phases.

\subsection{Sample collection}

One hundred unprocessed and fresh honey samples were collected randomly from various apiaries located in Northern Indian states during honey harvesting seasons. The information regarding botanical origins of samples was obtained from beekeepers. Floral origin was ascertained in relation to nearby locations and vegetation, where the beehives were installed. Honey samples weighing approximately $150 \mathrm{~g}$ were stored in amber coloured glass jars for a maximum of 4 weeks at $-20{ }^{\circ} \mathrm{C}$ to prevent any degradation and matrix alterations. Before laboratory analyses, samples were liquefied at room temperature. For quality control studies, one blank (reference) raw honey sample was also collected from a beehive placed in a rural area located in the Shivalik ranges of outer Himalayan region in India. The reference blank was confirmed for absence of any antibiotic contamination using validated methods for targeted antibiotics.

\subsection{Instrumentation}

For identification and quantification of oxytetracycline and erythromycin, Agilent 1260 infinity HPLC coupled with photo-diode array detector (DAD) supported by OpenLAB EZChrom software was used. For chloramphenicol estimation, MaxSignal ${ }^{\circledR}$ Chloramphenicol Enzyme Linked Immunosorbent Assay (CAP-ELISA) Test Kits (Product No. 1013-02F) purchased from BIOO Scientific ${ }^{\mathrm{TM}}$ Corp., USA were used. Absorbance of ELISA results was measured at $450 \mathrm{~nm}$ using Thermo Scientific ${ }^{\mathrm{TM}}$ Multiskan ${ }^{\mathrm{TM}} \mathrm{GO}$ microplate spectrophotometer. 


\subsection{Sample extraction and analyses}

The protocols of PAGLiUCIA and co-workers (2002) (for oxytetracycline), WANG (2004) (for erythromycin) and commercially available kit (for chloramphenicol) with slight modifications were followed for antibiotics determination in honeys.

For oxytetracycline, honey $(5 \mathrm{~g})$ was mixed with $20 \mathrm{ml}$ of $0.1 \mathrm{M} \mathrm{Na} \mathrm{N}_{2}$ EDTA-McIlvaine buffer ( $\mathrm{pH}$ 4.0). The sample solution was vortexed for $3 \mathrm{~min}$, followed by sonication for 10 min. Subsequently, mixture was centrifuged at $4000 \times g$ for $5 \mathrm{~min}$ at $25^{\circ} \mathrm{C}$. The supernatant was collected and filtered through Whatman filter paper No.1, and then finally passed through Oasis $^{\text {TM }}$ HLB 3cc $(60 \mathrm{mg})$ cartridge pre-conditioned with $1 \mathrm{ml}$ methanol and $1 \mathrm{ml}$ water. The cartridge was then washed with $10 \mathrm{ml}$ water and vacuum dried for $2 \mathrm{~min}$. Finally, sample was eluted with $1.5 \mathrm{ml}$ ethyl acetate. After evaporating the solvent at $40{ }^{\circ} \mathrm{C}$ in a vacuum concentrator, the extracted residues were re-dissolved in $1 \mathrm{ml}$ mobile phase, filtered through $0.22 \mu \mathrm{m}$ syringe filter, and $50 \mu \mathrm{l}$ was injected to the HPLC system. HPLC analysis was carried out using a Zorbax Eclipse XDB C-8, $(150 \times 4.6 \mathrm{~mm}$ i.d., $3 \mu \mathrm{m}$ particle size $)$ column (Agilent) maintained at $25{ }^{\circ} \mathrm{C}$ in isocratic conditions with mobile phase of aqueous oxalic acid $(10 \mathrm{mM})$, acetonitrile and methanol $(70: 15: 15, \mathrm{v} / \mathrm{v})$ at a flow rate of $0.5 \mathrm{ml} \mathrm{min}{ }^{-1}$. Total run time was $10 \mathrm{~min}$ including $1 \mathrm{~min}$ of equilibration time. The detector monitored the analyte at $360 \mathrm{~nm}$.

For erythromycin residues, honey $(2.5 \mathrm{~g})$ was mixed with $20 \mathrm{ml}$ of $0.1 \mathrm{M}$ phosphate buffer ( $\mathrm{pH} 8.0$ ). The solution was vortexed thoroughly and centrifuged at $4000 \times g$ for $5 \mathrm{~min}$ at $25{ }^{\circ} \mathrm{C}$. Upper layer was then carefully collected and filtered using a fluted Whatman ${ }^{\mathrm{TM}}$ filter paper No.1. The filtered sample solution was then passed through Oasis ${ }^{\mathrm{TM}}$ HLB $6 \mathrm{cc}$ $(200 \mathrm{mg}) \mathrm{SPE}$ cartridge pre-conditioned with methanol $(10 \mathrm{ml})$, water $(10 \mathrm{ml})$, and $\mathrm{NaCl}$ solution ( $10 \mathrm{ml}, 2 \%$ ) followed by equilibration using $2 \mathrm{ml}$ of $0.1 \mathrm{M}$ phosphate buffer $(\mathrm{pH}$ 8.0). The cartridge was then rinsed with $5 \mathrm{ml}$ water, $5 \mathrm{ml}$ of $40 \%$ methanol in water followed by vacuum drying for $5 \mathrm{~min}$. Finally, antibiotics were eluted using $5 \mathrm{ml}$ methanol under gravity. After evaporating the eluent at $40{ }^{\circ} \mathrm{C}$ in a vacuum concentrator, residues were redissolved in $1 \mathrm{ml}$ of mobile phase, filtered through $0.22 \mu \mathrm{m}$ syringe filter, and $100 \mu \mathrm{l}$ was injected to the HPLC system. For chromatographic separation, Zorbax Eclipse ODS C18 $\left(250 \times 4.6 \mathrm{~mm}\right.$ i.d., $5 \mu \mathrm{m}$ particle size) column (Agilent) at $40^{\circ} \mathrm{C}$ was used. The mobile phase consisting of $20 \mathrm{mM} \mathrm{K} 2 \mathrm{HPO} 4$ and acetonitrile $(40: 60, \mathrm{v} / \mathrm{v})$ was allowed to flow at the rate of $1.4 \mathrm{ml} \mathrm{min}{ }^{-1}$ with total run time of $10 \mathrm{~min}$ including $1 \mathrm{~min}$ of equilibration time. Detector monitored the eluent at $205 \mathrm{~nm}$.

For chloramphenicol residues, a microtiter plate-based, competitive colorimetric enzyme immunoassay was used. The sample preparation and testing protocol was employed strictly according to the manufacturer's instructions.

\subsection{Analytical performances and method validation}

For chromatographic analysis, method validation was carried out following the European Commission Decision 657/2002/EC (EC, 2002). Blank honey samples were spiked with oxytetracycline and erythromycin at three fortification levels and performance parameters were evaluated using matrix matched calibrations.

Linearity was assessed through six-point calibration curves with three replicates. Limit of detection (LOD) and limit of quantification (LOQ) were calculated from the calibration curve in accordance with International Conference on Harmonisation guidelines (ICH, 2005). Trueness (expressed as recovery \%) and precision (expressed as \% relative standard deviation) 
were measured by carrying out recovery experiments at three fortification levels. Ruggedness of the assay was demonstrated by following small amendments in the protocols. Selectivity of protocol was evaluated by injecting extracted blank honey samples and mobile phases. The lack of peaks at retention times of targeted antibiotics proved the exclusion of potential interfering compounds.

The performance criteria of CAP-ELISA kit were also verified by evaluating the linearity, detection limits, trueness, and precisions.

\subsection{Human health risk assessment}

For assessment of potential human health risks associated with oral intake of antibiotic residues through honey, estimated daily intakes (EDIs) were compared with the already established ADIs for all detected antibiotics to calculate Hazard Index (HI=EDI/ADI). EDI of residues was calculated for each antibiotic using the following equation:

$$
\mathrm{EDI}=\frac{\mathrm{C} \times \mathrm{F}}{\mathrm{D} \times \mathrm{W}}
$$

wherein, $\mathrm{C}$ is mean antibiotic residue concentration in honey $\left(\mu \mathrm{g} \mathrm{kg}^{-1}\right), \mathrm{F}$ is mean annual intake of honey per person in India, D is number of days in a year, and $\mathrm{W}$ is mean human body weight ( $60 \mathrm{~kg}$ for adults and $15 \mathrm{~kg}$ for children).

\section{Results and discussion}

\subsection{Method validation parameters}

The method performance parameters for antibiotics determination were found to be satisfactory (Table 1). Matrix matched calibration curves exhibited good linearity with coefficient of determination $>0.99$. The obtained LOD and LOQ values showed high method sensitivity for antibiotics. The methods showed high selectivity, without any interference close to the retention time of each compound. Mean recoveries $(85.2 \%$ to $90.4 \%)$ were within the acceptable range, and the relative standard deviation $\%$ was also found to be $<20 \%$.

The CAP-ELISA was also found to be linear in the range of $0.05-4.5 \mathrm{ng} \mathrm{g}^{-1}$. The mean recoveries obtained by spiking blank honey samples at three fortification levels were ranging between 77.3 to $83.1 \%$ (Table 1 ).

\subsection{Antibiotics in raw honey samples}

HPLC-DAD analyses of 100 raw honey samples comprising of 83 unifloral (originating from mustard, eucalyptus, Egyptian clover, litchi, coriander, cotton, jujube, rosewood tree, and sunflower) and 17 multifloral honeys revealed oxytetracycline residues in 25 samples with mean concentration of $69.3 \pm 5.7 \mathrm{ng} \mathrm{g}^{-1}$ (Table 2). Twenty-four samples contained oxytetracycline residues above the tolerance limit of $5 \mathrm{ng} \mathrm{g}^{-1}$ established by Food Safety and Standards Authority of India (FSSAI, 2014). Oxytetracycline concentrations ranging between 4.8 and $204 \mathrm{ng} \mathrm{g}^{-1}$ suggest that even though antibiotic usage in apiculture is not recommended by the National Bee Board of India, if not all, some beekeepers still continue the unadvised practice. This is further supported by the knowledge, attitude, and practices based study conducted during sampling, wherein $70 \%$ of small beekeepers believed in antibiotic usage 
for protection of beehives from diseases, and they were even unaware of the fact that antibiotics residues can appear in honey (KumAR et al., 2019). These results are in agreement with those reported for Indian honey by other authors (JoHNSON et al., 2010; RAO et al., 2015).

Table 1. Quality control parameters for antibiotics detection in honey

\begin{tabular}{|c|c|c|c|}
\hline Parameters & Oxytetracycline & Erythromycin & Chloramphenicol \\
\hline Analytical technique & HPCD-DAD & HPLC-DAD & Competitive ELISA \\
\hline Regression equation & $y=15004 x-18600$ & $y=55381 x-143883$ & $y=-18.101 x+40.995$ \\
\hline $\mathrm{R}^{2}$ & 0.9998 & 0.9998 & 0.9842 \\
\hline $\mathrm{LOD}\left(\mathrm{ng} \mathrm{g}^{-1}\right)$ & 1.62 & 1.58 & 0.05 \\
\hline LOQ (ng g $\left.{ }^{-1}\right)$ & 4.86 & 4.74 & 0.15 \\
\hline \multicolumn{4}{|l|}{ Recovery Studies $(\mathrm{n}=3)$} \\
\hline $\begin{array}{l}\text { Recovery } \pm \text { RSD } \% \text { at fortification } \\
\text { Level } 1\end{array}$ & $97.0 \pm 4.6$ & $89.2 \pm 4.6$ & $77.3 \pm 1.3$ \\
\hline $\begin{array}{l}\text { Recovery } \pm \text { RSD } \% \text { at fortification } \\
\text { Level } 2\end{array}$ & $83.9 \pm 2.3$ & $83.4 \pm 2.1$ & $83.1 \pm 0.7$ \\
\hline $\begin{array}{l}\text { Recovery } \pm \text { RSD } \% \text { at fortification } \\
\text { Level } 3\end{array}$ & $90.4 \pm 0.3$ & $82.9 \pm 1.7$ & $78.6 \pm 0.9$ \\
\hline Overall recovery\% (Trueness) & 90.4 & 85.2 & 79.7 \\
\hline RSDPOOLED \% (Precision) & 3.0 & 3.1 & 1.0 \\
\hline
\end{tabular}

Table 2. Antibiotic residues detected in raw honey samples $(\mathrm{N}=100)$

\begin{tabular}{lccccc}
\hline Antibiotics & $\mathrm{n}$ & Mean $\pm \mathrm{SD}^{\mathrm{a}}$ & $\begin{array}{c}\text { Minimum } \\
\text { quantified } \\
\left(\mathrm{ng} \mathrm{g}^{-1}\right)\end{array}$ & $\begin{array}{c}\text { Maximum } \\
\text { quantified } \\
\left(\mathrm{ng} \mathrm{g}^{-1}\right)\end{array}$ & $\begin{array}{c}\text { Samples above } \\
\text { MRLs }\end{array}$ \\
\hline Oxytetracycline & 25 & $69.3 \pm 5.7$ & 4.8 & 204 & 55.0 \\
Erythromycin & 2 & $53.0 \pm 2.8$ & 51.0 & - & 24 \\
Chloramphenicol & Not detected & - & - & & - \\
\hline
\end{tabular}

$\mathrm{n}=$ number of positive samples; ${ }^{\mathrm{a}}$ mean \pm standard deviation of positive samples

Of all honey samples, only two samples contained erythromycin with mean concentration of 53.0 $2.8 \mathrm{ng} \mathrm{g}^{-1}$. For comparison of obtained results, very few reports are available in published literature regarding presence of erythromycin residues in honey. JoHNSON and coworkers (2010) reported that $42 \%$ of market honey samples in India contained erythromycin residues with concentrations ranging from 69.7 to $280.3 \mathrm{ng} \mathrm{g}^{-1}$. In turkey, GuNES and coworkers (2008) found erythromycin in $8 \%$ of the honey samples with maximum content as high as $1776 \mathrm{ng} \mathrm{g}^{-1}$. However, present study revealing overall frequency of erythromycin in only $2 \%$ of the samples with maximum quantified concentration of $55 \mathrm{ng} \mathrm{g}^{-1}$ is relatively very low in comparison to some of the earlier studies. This could probably be attributed to nonavailability of erythromycin and frequent use of its cheaper analogues such as azithromycin or clarithromycin in India (BHATTACHARYA \& Sen, 2006), but such hypothesis needs to be tested in future studies.

Although, the use of chloramphenicol in food producing animals has been banned in many countries, there were reports of its detection in honey marketed in India (LuMPKIN, 2007). Subsequently, FSSAI (2014) established tolerance limit $\left(0.3 \mathrm{ng} \mathrm{g}^{-1}\right)$ for chloramphenicol 
residues in honey. Therefore, CAP-ELISA with detection limits of $0.05 \mathrm{ng} \mathrm{g}^{-1}$ was employed for its detection. None of the samples contained chloramphenicol residues. Hence, oxytetracycline was found to be the major antibiotic followed by erythromycin as contaminant in raw honey samples.

Antibiotics are also employed in orchards for treatment of various plant diseases. Therefore, their residues can obviously be found in honey bee products due to contaminated collected pollens. However, critical perusal of results revealed statistically non-significant correlation between antibiotic residues and floral origin of honey. Therefore, it might be safe to hypothesise that the antibiotic residues in honey originated largely from incautious apicultural practices and certainly not from horticultural/environmental sources.

Oxytetracycline is the most frequently used antibiotic to treat bacterial foulbrood diseases of honey bees. However, there are reports of tetracycline resistance in these bacteria. Therefore, recently, alternate antibiotics such as erythromycin and chloramphenicol have been administered to bee colonies by beekeepers (Mahmoudi \& PAKbin, 2015). This could be the reason for the use of antibiotics in apiculture settings despite various restrictions and limits imposed by the government on their use. Due to stringent regulations on food safety, there has been a substantial decrease in occurrence of antibiotics in honey, especially from Indian, American, and European markets (REYBROECK, 2018; USFDA, 2019), but even the trace presence of such contaminant is alarming and potentially dangerous for consumers' health, and therefore, needs utmost attention.

\subsection{Human health risk assessment}

The HI value was $<1$ i.e. intake of antibiotic residues through honey remains clearly below the safe limits (Table 3). The human health risk assessment signifies that there are no acute effects and there is negligible risk to consumers' health at current levels of honey contamination and consumption pattern. But continuous, sub-therapeutic, and long term exposures of these antibiotics can pose significant risk to human health. Therefore, health education of beekeepers, routine monitoring of antibiotic residues in honey, and precautionary measures, especially while feeding infants, old and ill people, should always be carefully considered to safeguard human health.

Table 3. Estimated daily intakes and percent contribution to acceptable daily intakes of antibiotic residues from raw honey

\begin{tabular}{lccccc}
\hline Antibiotics & \multirow{2}{*}{$\begin{array}{c}\text { ADI } \\
(\mu \mathrm{g} / \mathrm{kg} \text { b.wt/day })\end{array}$} & Age Group & \multicolumn{3}{c}{ Honey samples } \\
\cline { 4 - 6 } & & & EDI & HI & \% ADI \\
\hline Oxytetracycline & 3.0 & Adult & $2.22 \mathrm{E}-04$ & $7.38 \mathrm{E}-05$ & $7.38 \mathrm{E}-03$ \\
& & Children & $1.33 \mathrm{E}-03$ & $4.43 \mathrm{E}-04$ & $4.43 \mathrm{E}-02$ \\
Erythromycin & \multirow{2}{*}{0.7} & Adult & $1.69 \mathrm{E}-04$ & $2.42 \mathrm{E}-04$ & $2.42 \mathrm{E}-02$ \\
& & Children & $1.02 \mathrm{E}-03$ & $1.45 \mathrm{E}-03$ & $1.45 \mathrm{E}-01$ \\
\hline
\end{tabular}

\section{Conclusions}

In conclusion, honey samples were found to contain oxytetracycline residues relatively in higher proportions as compared to other targeted antibiotics. The occurrence of antibiotic residues in honey suggests poor management practices followed by the distressed beekeepers 
for avoiding economic losses and saving their beehives from infectious diseases. Therefore, to avoid any injudicious use or misuse of antibiotics in apicultural practices, there is an urgent need to increase the awareness levels of beekeepers on beehive management and simultaneously of consumers on food safety and human health issues. Furthermore, effective enforcement of food safety regulations and nationwide continuous residue monitoring programs are of utmost essentiality to preclude contamination of honey.

Authors express their gratitude to beekeepers for their invaluable contribution during sample collection and Guru Angad Dev Veterinary and Animal Sciences University, Ludhiana, Punjab for providing necessary facilities to carry out the present research.

\section{References}

Bhattacharya, B.K. \& SEN, S.K. (2006): Antibiotics buisness: A glimpse. Indian J. Biotechnol., 5, 471-476. EC (2002): European Commission regulation of 2002/657/E: Implementing council directive 96/23/EC concerning the performance of analytical methods and the interpretation of results. O.J. Eur. Comm., 2002, L 221/8-L $221 / 36$

FSSAI (Food SAFETy AND STANDARD Authority of INDiA) (2014): Food Safety and Standards (contaminants, toxins and residues) Amendment Regulations, 2014. Regulation No. 2.3.2. Gazette of India, Extraordinary, Part III, Section 4 vide ADVT.III/4/Exty./191/F/2104.

Gunes, N., CibiK, R., Gunes, M.E. \& Aydin, L. (2008): Erythromycin residue in honey from the Southern Marmara region of Turkey. Food Addit. Contam. A., 25, 1313-1317.

ICH (2005): Harmonised tripartite guideline validation of analytical procedures: Text and methodology; Q2 (R1). International Conference on Harmonisation.

Johnson, S., Jadon, N., Mathur, H.B. \& Agarwal, H.C. (2010): Antibiotic residues in honey. http://www.scribd. com/doc/38591126/7/Review-of-Literature. (Last accessed January 8, 2018)

Kumar A., Gill, J.P.S., Bedi, J.S. \& Kumar, A. (2018): Pesticide residues in Indian raw honeys, an indicator of environmental pollution. Environ. Sci. Pollut. R., 25, 34005-34016.

Kumar, A., Gill, J.P.S., Bedi, J.S. \& ChHuneJA, P.K. (2019): Health risks associated with antibiotics and pesticides in honey: knowledge, attitude and practices of beekeepers in India. Indian J. Vet. Public Health, 16(1), 1-9.

Lumpkin, M.M. (2007): Safety of Chinese imports: Oversight and analysis of the federal response. Testimony before the senate committee on commerce, science, and transportation. 2007. Available at https://www.uschamber. com/china-policy-resources. (Last accessed: 18 March 2019)

Mahmoudi, R., Moosavy, M., Norian, R., Kazemi, S., Nadari, M.R.A. \& Mardani, K. (2014): Detection of oxytetracycline residues in honey samples using ELISA and HPLC methods. Pharm. Sci., 19, 145-150.

Mahmoudi, R. \& Pakbin, B. (2015): An overview of the hazards and management strategies for antibiotic residue in honey. Int. J. Food Saf. Nutr. Publ. Health, 6, 1-9.

Pagliuca, G., Gazzotti, T., Serra, G. \& Sabatini, A.G. (2002): A scientific note on the determination of oxytetracycline residues in honey by high-performance liquid chromatography with UV detection. Apidologie, 33, 583-584.

RaO, C.R.M., Kumar, L.C.A. \& SeKharan, C.B. (2015): Quantitative analysis of oxytetracycline residues in honey by high performance liquid chromatography. Int. Res. J. Biol. Sci., 4, 59-65.

ReybroecK, W. (2018): Residues of antibiotics and chemotherapeutics in honey. J. Apicult. Res., 57, 97-112.

Solomon, R., SANTHI, V.S. \& Jayaraj, V. (2006): Prevalence of antibiotics in nectar and honey in South Tamilnadu, India. Integrative Biosciences, 10, 163-167.

USFDA (2019): Import Alert 36-04. Detention without physical examination of honey and blended syrup due to unsafe drug residues. Available at https:/www.accessdata.fda.gov/cms_ia/importalert_111.html (Last accessed 25 August 2019)

Venable, R., Haynes, C. \& Cook, J.M. (2014): Reported prevalence and quantitative LC-MS methods for the analysis of veterinary drug residues in honey: a review. Food Addit. Contam. A., 31, 621-640.

WANG, J. (2004): Determination of five macrolide antibiotic residues in honey by LC-ESI-MS and LC-ESI-MS/MS. J. Agr. Food Chem., 52(2), 171-181. 